\title{
Formation of Iron-Containing Clusters in Silica of Predetermined Porosity
}

\author{
I. ŠIMKIENE ${ }^{a, *}$, M. BARAN ${ }^{b}$, G.-J. BABOnAS ${ }^{a, c}$, \\ R.-A. Bendorius ${ }^{a, c}$, A. RĖzA ${ }^{a}$, R. SzYMCZAK $^{b}$, \\ P. AleshrevyCH ${ }^{b}$, R. ŠustaviČIŪtét ${ }^{a}$ And R. TAmašEviČIUs ${ }^{a}$ \\ ${ }^{a}$ Semiconductor Physics Institute, Goštauto 11, 01108 Vilnius, Lithuania \\ ${ }^{b}$ Institute of Physics, PAS, al. Lotników 32/46, 02-668 Warszawa, Poland \\ ${ }^{c}$ Vilnius Gediminas Technical University, Saulettekio 11, 10223 Vilnius, Lithuania \\ Iron-containing nanoparticles and clusters were formed in silica with \\ porosity, which was predetermined by different procedures of sol-gel tech- \\ nology and the chemical composition of precursors. Bulk and layer-type \\ samples of different porosity were synthesized and investigated. The mor- \\ phology, magnetic, and optical properties were studied to characterize the \\ samples and to analyze the formation of Fe-oxides. Experimental results \\ showed that both $\mathrm{Fe}_{2} \mathrm{O}_{3}$ and $\mathrm{Fe}_{3} \mathrm{O}_{4}$ were formed in the samples and that \\ their relative amount was dependent on preparation technology.
}

PACS numbers: $61.46 .+\mathrm{w}, 75.75 .+\mathrm{a}, 78.66 .-\mathrm{w}$

\section{Introduction}

Recently, the systems of iron-containing clusters embedded in oxide silica matrix have been widely studied due to their potential applications [1], in particular as magnetic recording media. However, the magnetic behavior of iron-containing nanoparticles was strongly dependent on technology of sample preparation [2]. Magnetite $\left(\mathrm{Fe}_{3} \mathrm{O}_{4}\right)$ nanorods and porous hematite $\left(\alpha-\mathrm{Fe}_{2} \mathrm{O}_{3}\right)$ nanorods were prepared [3] through hydrolysis of $\mathrm{FeCl}_{3}$ and $\mathrm{FeSO}_{4}$ solutions. Nanoparticles of $\alpha-\mathrm{Fe}_{2} \mathrm{O}_{3}$ with a closed cage structure were formed [4] by a low-temperature hydrothermal method from aqueous solution of $\mathrm{FeCl}_{3}$ and cetyltrimethylammonium bromide (CTAB).

The sol-gel method is mostly perspective for preparation of magnetic nanocomposites embedded in dielectric matrix-like silica. However, a gelation process and the formation of final nanocomposites were strongly influenced [5] by the surface-to-volume ratio and later heat treatments. Therefore, it is reasonable

*corresponding author; e-mail: irena@pfi.lt 
to assume that the porosity of matrix plays a crucial role in the formation of iron-containing particles and clusters.

In this work Fe-containing clusters were formed and investigated in silica of porosity, which has been predetermined by different procedures of sol-gel technology and by varying the composition of precursors. Three groups of samples were synthesized and investigated: (i) bulk sol samples of high porosity prepared by a hydrolysis of tetraethoxysilane (TEOS)-based solutions; (ii) low-porosity Fe-containing silica layers produced by sol-gel spin-on technique on Si substrates using precursors $\mathrm{TEOS}+\mathrm{FeCl}_{3}$; (iii) high-porosity Fe-containing silica layers prepared by spin coating on Si substrates from precursors with surfactant CTAB.

Morphology of synthesized samples was studied by scanning electron microscopy (SEM) and atomic force microscopy (AFM). The magnetic and optical properties were investigated to characterize the samples and to analyze the formation of Fe-oxides.

\section{Experimental}

Bulk samples of iron-containing silica were prepared by mixing the aqueous solution of $\mathrm{FeCl}_{3}$ and TEOS $\left(20 \mathrm{ml} \mathrm{Si}\left(\mathrm{C}_{2} \mathrm{H}_{5} \mathrm{O}\right)_{4}+40 \mathrm{ml} \mathrm{C}_{2} \mathrm{H}_{5} \mathrm{OH}+4 \mathrm{ml} \mathrm{H}_{2} \mathrm{O}+\right.$ $0.1 \mathrm{ml} \mathrm{HCl}$ ) in volume ratio 1:3. Several drops of ammonia were added to reach a pH-value equal to 5 . Clear sols were obtained in ultrasound bath in $1 \mathrm{~h}$ and gelated at $300 \mathrm{~K}$ in air for 10 days. The gels were dried at $100^{\circ} \mathrm{C}$ for $8 \mathrm{~h}$ and annealed in $\mathrm{Ar}$ or hydrogen at $550^{\circ} \mathrm{C}$ for $2 \mathrm{~h}$.

The sol of composition described above was used as precursor for spin-coating of Si substrates ( $n$-Si (100)-oriented wafers, $0.5 \Omega \mathrm{cm}$ ). Si substrates were previously coated by two silica layers from TEOS solution making use of the spin-on technique. Each silica layer of thickness $\approx 150 \mathrm{~nm}$ were dried at $300^{\circ} \mathrm{C}$ for $1 \mathrm{~h}$. The structure of the samples represent a multi-layer stack on substrate, two pure silica layers and two Fe-doped silica layers. The samples were annealed in air, $\mathrm{Ar}$ or $\mathrm{H}_{2}$ at $500^{\circ} \mathrm{C}$ for $2 \mathrm{~h}$.

The other samples were obtained by sol-gel spin-on technique from precursors with surfactant CTAB. In one case $0.84 \mathrm{~g} \mathrm{FeCl}_{3}, 0.6 \mathrm{~g}$ CTAB were dissolved in $40 \mathrm{ml} \mathrm{H}_{2} \mathrm{O}$ and stirred in the ultrasound bath for 30 min until homogeneous yellow sol was formed. The solution was deposited on substrate in centrifuge (2500 rpm). In the second case the solution described above was mixed with TEOS in volume ratio $1: 1$ and used for spin-coating. The samples were dried at $80^{\circ} \mathrm{C}$ for $4 \mathrm{~h}$ and some samples were annealed in air at $550^{\circ} \mathrm{C}$ for $1 \mathrm{~h}$.

Magnetic properties of complex structures were studied using a commercial SQUID magnetometer (MPMS-5, Quantum Design). The magnetization was measured in the temperature range $5-300 \mathrm{~K}$ in magnetic fields up to $50 \mathrm{kOe}$. The magnetic field was oriented in the plane of the films.

The optical properties of synthesized samples were studied by null- and spectroscopic ellipsometry, photoluminescence, and optical transmission measurements. Spectroscopic ellipsometry measurements were carried out at $300 \mathrm{~K}$ in 
the range 1-5 eV by means of a photometric ellipsometer with rotating analyzer. The experimental data were analyzed in a model of multilayer structure. The ellipsometric parameters $\Psi$ and $\Delta$ were directly calculated by solving the Maxwell equations using the transfer matrix technique.

Photoluminescence was excited by Ar-ion laser ILT5000 (50 mW at $488 \mathrm{~nm}$ ). The photoluminescence spectra were obtained by means of monochromator MDR-12 using the grating of 1200 lines/mm.

The physical properties of iron-containing silica layers were correlated with the structural features studied by SEM and AFM techniques.

\section{Results and discussion}

\subsection{Bulk samples}

Different iron oxides can be formed in bulk samples. When precursor with $\mathrm{FeCl}_{3}$ was used, $\beta$-FeOOH was usually formed which transformed to $\alpha-\mathrm{Fe}_{2} \mathrm{O}_{3}$ after heat treatment [6]. However, in contrast to other studies, in this work, the colloidal TEOS solution was used in which polymer-like chains $\mathrm{O}-\mathrm{Si}-\mathrm{O}-\mathrm{Si}$ have been already formed. For this reason, the final composites could differ from those observed earlier [6] and various iron oxides could be formed.
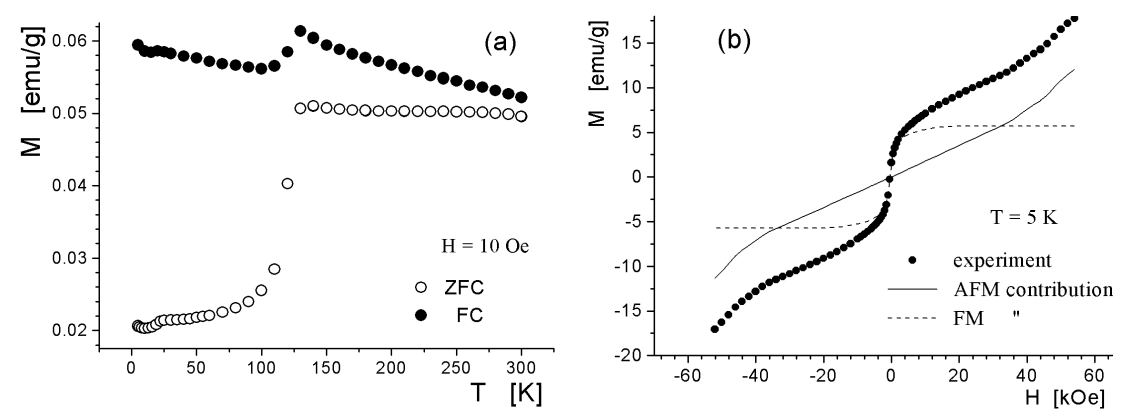

Fig. 1. Temperature (a) and magnetic field dependence (b) of magnetization for bulk samples annealed in Ar.

Figure 1 illustrates the magnetic properties of the bulk samples annealed in Ar. The temperature dependence of magnetization at low magnetic field of 10 Oe and the difference between field-cooled (FC) and zero-field cooled (ZFC) data were similar to those observed in [7] for large nanoparticles of magnetite of size $150 \mathrm{~nm}$. A phase transition occurs near $130 \mathrm{~K}$, which correlates to the Verwey transition in $\mathrm{Fe}_{3} \mathrm{O}_{4}$. At higher magnetic fields (20 and $50 \mathrm{kOe}$ ) the magnetization increased but the difference between FC and ZFC as well as the feature at $130 \mathrm{~K}$ disappeared. Some peculiarity in $M(T)$ behavior was also observed at $\approx 20 \mathrm{~K}$. It should be noted that the characteristic Verwey temperature was found [7] to shift from 98 to $\approx 20 \mathrm{~K}$ as the size of nanoparticles was reduced from 150 to $50 \mathrm{~nm}$. However, 
the peculiarities at $\approx 130 \mathrm{~K}$ and $\approx 20 \mathrm{~K}$ are of different origin because of their quite different behavior at magnetic field changes.

Magnetic field dependence of magnetization $M(H)$ (Fig. 1) has shown a lack of saturation (both at 5 and $300 \mathrm{~K}$ ) and a bend (at $5 \mathrm{~K}$ ) in about $40 \mathrm{kOe}$, which could be interpreted as the field-induced magnetic phase transition. $M(H)$ approached at $300 \mathrm{~K}$ the value of $6 \mathrm{emu} / \mathrm{g}$, which is significantly lower than that for nanoparticles of pure $\mathrm{Fe}_{3} \mathrm{O}_{4}$ [7]. All the facts could suggest that beside the ferrimagnetic contribution there is also some of antiferromagnetic (AFM) type, let us say of $\alpha-\mathrm{Fe}_{2} \mathrm{O}_{3}$ or FeSi. In this case the kink at $20 \mathrm{~K}$ for $M(T)$ in high magnetic fields could be ascribed to the Morin-type transition from weak FM to AFM structure in $\alpha-\mathrm{Fe}_{2} \mathrm{O}_{3}$ with a large shift of the characteristic temperature due to the formation of nanoparticles. The hysteresis loop measurements have shown that the coercive force amounts to $\approx 500$ and 200 Oe at 5 and $300 \mathrm{~K}$, respectively. The remanence-to-saturation ratio is smaller than 0.5 indicating the existence of interparticle interactions of AFM nature.

The magnetization of $\mathrm{H}_{2}$-annealed bulk samples was considerably higher than that of Ar-annealed samples. No clear manifestation of phase transition was observed though some peculiarity was noticed at $\approx 50 \mathrm{~K}$. The $\mathrm{FM} /$ ferrimagnetic or supermagnetic contributions were expected from the temperature dependence $M(T)$, which was quite similar to that [8] for oxide-coated Fe cluster assemblies of $5-10 \mathrm{~nm}$ in size. The FC magnetization weakly depended on temperature and the remanence decreased only by $20 \%$ as the temperature increased from 5 to $300 \mathrm{~K}$ indicating a high value of the Curie temperature. The magnetic field dependence of magnetization was similar at 5 and $300 \mathrm{~K}$ showing at $\approx 10 \mathrm{kOe}$ the tendency for saturation at $45 \mathrm{emu} / \mathrm{g}$. The latter value was smaller than that $(76 \mathrm{emu} / \mathrm{g})$ for bulk $\gamma-\mathrm{Fe}_{2} \mathrm{O}_{3}$ but was higher than that for nanoparticles of $\approx 10 \mathrm{~nm}$ [1]. The coercive force was equal to $\approx 100$ Oe and was weakly dependent on temperature as was determined for silica-coated Fe particles of $35 \mathrm{~nm}$ [9]. It should be noted that in the latter case the saturation magnetization at $5 \mathrm{~K}$ was strongly dependent on calcination temperature for a constant particle size [9].

As follows from the data presented above, the most probable explanation of the observed experimental data is that the bulk samples contain both magnetite $\left(\mathrm{Fe}_{3} \mathrm{O}_{4}\right)$ and hematite $\left(\alpha-\mathrm{Fe}_{2} \mathrm{O}_{3}\right)$ particles. The maghemite $\left(\gamma-\mathrm{Fe}_{2} \mathrm{O}_{3}\right)$ particles were usually accompanied by hematite in Fe-oxide - silica aerogel and xerogel samples [10]. In the investigated bulk samples most probable contributions were originated from magnetite and hematite in Ar-annealed samples whereas maghemite and $\mathrm{Fe}$ nanoparticles coated by iron oxides contribute mainly to magnetization of $\mathrm{H}_{2}$-annealed samples.

\subsection{Dense Fe-containing silica layers on Si substrates}

In the silica layers deposited on Si substrates by sol-gel spin-on technique large clusters and small nanosized particles were observed. A granular structure 


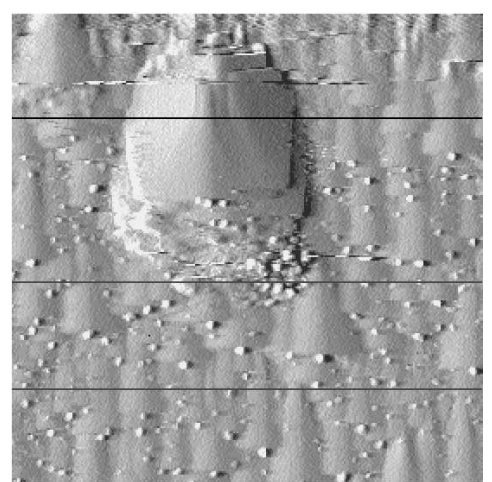

Fig. 2. AFM image of Fe-containing silica layer annealed in $\mathrm{H}_{2}$. The area shown is $5 \times 5 \mu \mathrm{m}^{2}$.

with grains of $1-2 \mu \mathrm{m}$ in size and $\approx 200 \mathrm{~nm}$ in height was observed on the surface of layers annealed in air or Ar. Large defects of size $20-40 \mu \mathrm{m}$ with a higher Fe-content [11] were also formed. In the silica layers annealed in $\mathrm{H}_{2}$ (Fig. 2) the grains were smaller (200-500 $\mathrm{nm}$ in size) though some larger grains (up to $1 \mu \mathrm{m})$ were also noticed. Nanosized particles $(\varnothing 10-40 \mathrm{~nm})$ could be assigned to iron/iron oxide formations.

Silica layers deposited on Si substrates by sol-gel spin-on technique were denser than bulk silica samples. The refractive index of silica layers prepared from acid-based precursors with $\mathrm{pH} \approx 2$ was equal to $1.42-1.43$ as followed from null-ellipsometry measurements at $633 \mathrm{~nm}$. Taking into account the refractive index of thermal oxide $(n=1.45)$ the porosity of silica layers were estimated to be of order $5-10 \%$.

The photoluminescence spectra (Fig. 3) were different for samples produced under various technological conditions. In the case of precursors $\mathrm{TEOS}+\mathrm{FeCl}_{3}$ without surfactant, the photoluminescence bands at $\approx 675,750$, and $825 \mathrm{~nm}$ were observed for annealed samples. These bands were resolved in the spectra of almost

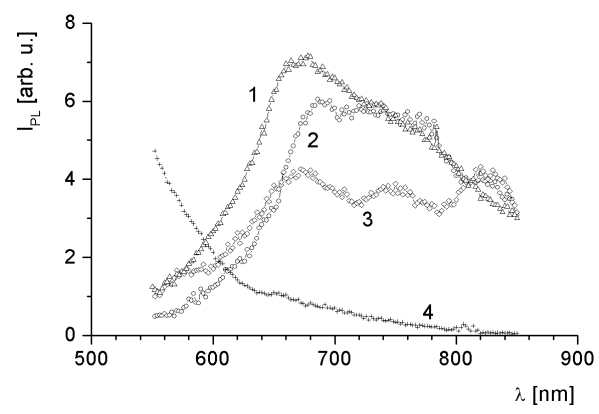

Fig. 3. Photoluminescence spectra of Fe-containing silica layers produced from precursors with (1) and without $(2-4)$ surfactant, with $\mathrm{pH}$-value $\approx 2(2)$ and $\approx 5(3,4)$ at $\mathrm{FeCl}_{3}$ :TEOS ratio $1: 3(3,4)$ and 1:1 (2) annealed in air $(2,3)$ and $\mathrm{H}_{2}(4)$. 
all the samples but with various relative intensities. At an increase in Fe-amount, broad band at 670-800 nm was formed. In the samples prepared from TEOS-based precursors with surfactant the band at $670 \mathrm{~nm}$ was dominant.

The difference in the fine structure of photoluminescence spectra is most probably caused by the formation of various Fe oxides in the silica layers. The spectral position of the photoluminescence band at $\approx 670 \mathrm{~nm}$ correlates with the absorption edge of $\mathrm{Fe}_{2} \mathrm{O}_{3}$ [12]. The photoluminescence bands at longer wavelengths can be related to the optical features in $\mathrm{Fe}_{3} \mathrm{O}_{4}$ [13] and are most developed in the samples with the largest iron amount in precursor. In the photoluminescence spectra of the samples annealed in $\mathrm{H}_{2}$ the contribution of band at $\lambda<550 \mathrm{~nm}$ was determined and could be related to the formation of Fe-containing nanoparticles in silica layers.

Spectroscopic ellipsometry data were well described by a multi-layer model, which took into account the presence of different iron oxides in silica and in-depth variation of porosity. Figure 4 illustrates ellipsometric data for Fe-doped silica layer prepared from base-based precursor and annealed in $\mathrm{H}_{2}$. The sample was modeled by the stack of porous layers of Fe particles, non-homogeneous composite layers of $\mathrm{Fe}_{3} \mathrm{O}_{4}$ and $\mathrm{SiO}_{2}$, and substrate.

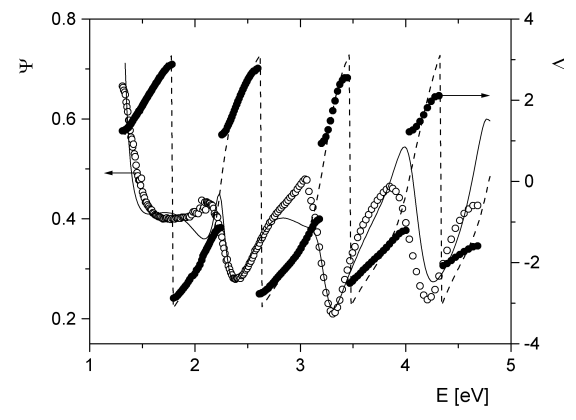

Fig. 4. Experimental (points) and modeled (curves) spectra of ellipsometric parameters for Fe-containing silica layer prepared from base-based precursor with $\mathrm{pH} \approx 5$ and annealed in $\mathrm{H}_{2}$.

Magnetic properties of Fe-containing silica layers grown on Si substrates from the precursors used for bulk samples were quite close to those observed for bulk samples with respect to coercive force and the absence of saturation in the $M(H)$ dependence. The coercive force was equal to $\approx 400$ and $\approx 700$ Oe at $5 \mathrm{~K}$ and the blocking temperature was near 200 and $350 \mathrm{~K}$ for samples annealed in $\mathrm{Ar}$ and $\mathrm{H}_{2}$, respectively. The $M(H)$ dependences were close to those for their bulk counterparts. The peculiarity observed at $50 \mathrm{~K}$ in the $M(T)$ dependence for $\mathrm{H}_{2}$-annealed samples was similar to that [14] determined for nanostructures in mesoporous silica matrix. It should be remarked that $M(H)$ and $M(T)$ dependences were close to those for the layers prepared from precursors of a higher acidity $(\mathrm{pH} \approx 2)[11]$. 


\subsection{Porous Fe-doped silica layers prepared with surfactant}

Figure 5 shows the SEM micrographs of the samples prepared from TEOS solution with surfactant CTAB. On the surface of silica layer pores of 20-100 nm were observed, the number of which increased after annealing of the samples in air. Iron and iron oxides were most presumably located at pores and large defects of size $\approx 1 \mu \mathrm{m}$. Direct measurements of cross-sections indicated that the layers were not homogeneous with thickness varying in the range $30-80 \mathrm{~nm}$.

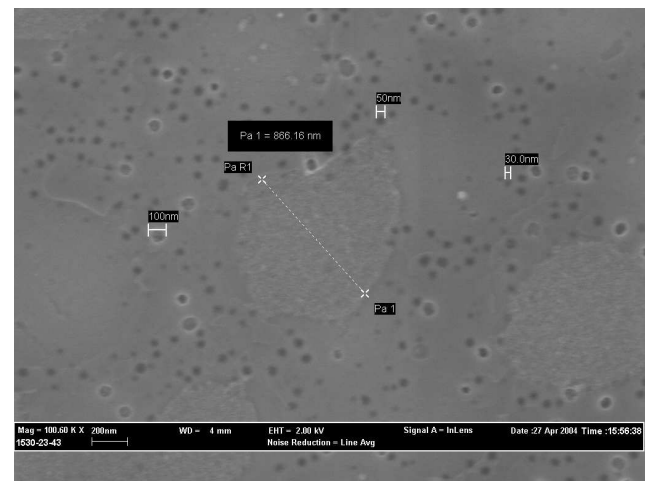

Fig. 5. SEM micrograph of Fe-containing silica layers prepared from TEOS solutions with surfactant CTAB after annealing. Bar denotes $100 \mathrm{~nm}$.

Null-ellipsometry measurements have shown a large porosity in this series of samples. The estimated values of refractive indexes at $633 \mathrm{~nm}$ were equal to 1.32 and 1.39 for dried and annealed samples, respectively. A significant absorption should be mentioned which was indicated from the estimated values of imaginary part of dielectric function $\varepsilon_{2}$ equal to $\approx 0.2$ for dried layers and $\approx 0.1$ for annealed ones. Direct studies of coating solutions deposited on glass substrates have shown the absorption threshold at $\approx 2 \mathrm{eV}$ with a strong peak at $\approx 3.4 \mathrm{eV}$. These optical features are typical of $\mathrm{Fe}_{2} \mathrm{O}_{3}$ [12]. A further absorption increase could be due to the presence of $\mathrm{Fe}_{3} \mathrm{O}_{4}$ [13].

Spectroscopic ellipsometry studies have shown that the spectra can be modeled by several layers of thickness $5-50 \mathrm{~nm}$ each presenting the contributions of Lorentzian-type lines. As followed from fitting procedure, the optical features were located at $1.0,1.9,3.3$, and $4.6 \mathrm{eV}$. These energies were in agreement with characteristic features in $\mathrm{Fe}_{2} \mathrm{O}_{3}[12]$ and $\mathrm{Fe}_{3} \mathrm{O}_{4}$ [13]. The high-energy feature was stronger in annealed sample indicating an increased contribution of $\mathrm{Fe}_{3} \mathrm{O}_{4}$.

The magnetization of this type of Fe-doped silica layers appeared to be so small that it was impossible to estimate it even roughly on a strong background of substrate contribution. The small value or absence of Fe contribution could be caused by either low amount of iron/iron oxide in these very thin layers or by a singular Fe state in this case. 
Summarizing, the structural, magnetic and optical studies have shown that the physical properties of Fe-containing silica layers can be efficiently changed by varying the porosity of medium. The size of formations containing iron and iron oxides was in the range from $20 \mathrm{~nm}$ to $50 \mu \mathrm{m}$ and was strongly influenced by the porosity of silica layers.

\section{Acknowledgments}

This work was partly supported by EP6 project PHOREMOST N 511616.

\section{References}

[1] R.F. Ziolo, E.P. Giannelis, B.A. Weinstein, M.P. O'Horo, B.N. Ganguly, V. Mehrota, M.W. Russel, D.R. Huffman, Science 257, 219 (1992).

[2] C. Caiser, C. Savii, M. Popovici, Mater. Sci. Eng. B 97, 129 (2003).

[3] S. Lian, E. Wang, Z. Kang, Y. Bai, L. Gao, M. Jiang, C. Hu, L. Xu, Solid State Commun. 129, 485 (2004).

[4] X. Wang, X. Chen, X. Ma, H. Zheng, M. Ji, Z. Zhang, Chem. Phys. Lett. 384, 391 (2004).

[5] S. Solinas, G. Piccaluga, M.P. Morales, C.J. Serna, Acta Mater. 49, 2805 (2001).

[6] F. del Monte, M.P. Morales, D. Levy, A. Fernandez, M. Ocana, A. Roig, E. Molins, K. O'Grady, C.J. Serna, Langmuir 13, 3627 (1997).

[7] G.F. Goya, T.S. Berquo, F.C. Fonseca, M.P. Morales, J. Appl. Phys. 94, 3520 (2003).

[8] D.L. Peng, T. Hihara, K. Surmiyama, H. Morikawa, J. Appl. Phys. 92, 3075 (2002).

[9] M. Wu, Y.D. Zhang, S. Hui, T.D. Xiao, S. Ge, W.A. Hines, J.I. Budnick, M.J. Yacaman, J. Appl. Phys. 92, 6809 (2002).

[10] M.F. Casula, A. Corrias, G. Paschina, J. Non-Cryst. Solids 293-295, 25 (2001).

[11] I. Šmkiene, J. Sabataityte, J. Babonas, A. Reza, R. Szymczak, H. Szymczak, M. Baran, M. Kozlowski, S. Gierlotka, Proc. SPIE, accepted for publication.

[12] N. Ozer, F. Tepehan, Solar Energy Mater. Sol. Cells 56, 141 (1999).

[13] W.F. Fontijn, P.J. van der Zaag, M.A.C. Devillers, V.A.M. Brabers, R. Metselaar, Phys. Rev. B 56, 5432 (1997).

[14] K.S. Napolsky, A.A. Eliseev, A.V. Knotko, A.V. Lukashin, A.A. Vertegel, Yu.D. Tret'yakov, Mater. Sci. Eng. C 23, 151 (2003). 